\title{
Effect of quercetin on the brain-derived neurotrophic factor gene expression in the rat brain
}

\author{
Rahvar $\mathrm{M}^{1}$, Owji AA², Mashayekhi $\mathrm{FJ}^{3}$ \\ Department of Medical Nanotechnology School of Advanced Technologies in Medicine, Tehran University \\ of Medical Sciences, Tehran, Iran. mashayekhi@arakmu.ac.ir
}

\begin{abstract}
INTRODUCTION: Quercetin is a ubiquitous flavonoid found in many plants. Neuroprotective effects of quercetin have been shown in several in vitro and in vivo studies, but its mechanism of action has not been fully defined yet. Brain-derived neurotrophic factor (BDNF) is a fundamental neurotrophin with vital functions in the survival of neuronal cells. In the present study, we aimed to investigate the effects of quercetin on expression of BDNF mRNA in the hippocampus of rat brain.

METHODS: Male rats were daily gavaged with quercetin $(10,20$ or $50 \mathrm{mg} / \mathrm{kg} \cdot \mathrm{bwt})$ for 30 days. Hippocampal levels of the BDNF transcripts were assessed using quantitative (q) RT-PCR.

RESULTS: Quercetin at doses of 20 and $50 \mathrm{mg} / \mathrm{kg}$ caused a significant increase in the mRNA expression of BDNF as compared with the control group. Quercetin treatment at a dose of $10 \mathrm{mg} / \mathrm{kg}$ failed to cause any significant changes in the levels of BDNF mRNA

CONCLUSION: Our findings suggest that the neuroprotective effects of quercetin may be at least partly due to its inducing effects on the expression levels of the BDNF mRNA (Fig. 1, Ref. 40). Text in PDF www.elis.sk. KEY WORDS: BDNF, quercetin, hippocampus, rat.
\end{abstract}

\section{Introduction}

Neurodegenerative diseases are mostly age related diseases, resulting from deterioration of neurons or their myelin sheaths that will lead to dysfunction and disability (1). Growing body of evidence suggests that neuro-inflammation and oxidative stress are implicated in the pathophysiology of neurodegenerative diseases such as Parkinson's disease (PD) and Alzheimer's disease (AD) (2).

Plant metabolites including flavonoids and alkaloids being powerful antioxidants, play protective roles in several oxidative stress-mediated diseases $(3,4)$. A growing body of evidence from animal models to clinical studies indicates that dietary flavonoids protect neurons against injury and promote memory, learning and cognitive function $(3,5)$. Neuroprotective effects of flavonoids are mainly explained by their free radical scavenger properties, involvement in intracellular signaling pathway and mitochondrial dysfunction, as well as control of processes as inflammation, apoptosis, and production of BDNF (6). In our previous studies,

${ }^{1}$ Department of Medical Nanotechnology School of Advanced Technologies in Medicine, Tehran University of Medical Sciences, Tehran, Iran, ${ }^{2}$ Research Center for Psychiatry and Behavioural Sciences, Shiraz University of Medical Sciences, Shiraz, Iran, and ${ }^{3}$ Department of Biochemistry and Genetics, Faculty of Medicine, Arak University of Medical Sciences, Arak, Iran

Address of correspondence: F.J. Mashayekhi PhD, Department of Biochemistry and Genetics, Arak University of Medical Sciences, Arak, Iran. Phone: +989188614706, Fax: +988634173505

Acknowledgements: This paper was supported by Grant Number 3492 from Medicinal and Natural Products Chemistry Research Center - Vicechancellor for Research Affairs of Shiraz University of Medical Sciences. we showed that the polyphenol stilbene, resveratrol, increased the expression of BDNF transcripts in the hippocampus of rats (7).

Quercetin (3,5,7,30,40-pentahydroxyflavone), is a member of the flavonoid family of polyphenols that is generally found in fruits and vegetables such as onions, apples and blueberries. Quercetin attracted intense interest for its potentially beneficial effects on human health. The protective effects of quercetin against various diseases such as pulmonary diseases, cardiovascular diseases, cancer, and neurodegenerative disorders have been shown by many researchers in epidemiological studies $(8,9)$.

Quercetin is shown to modulate the intracellular signaling pathways. The effects of quercetin on the expression of pro-survival proteins appear to be an important mechanism for its neuronal protection properties. Quercetin also regulates the activity of kinases, changing the phosphorylation state of target molecules, resulting in modulation of cellular function and gene expression $(10,11)$.

A growing body of evidence indicates that neurotrophic factors such as BDNF play key roles in the development and survival of neurons (12). BDNF is the most abundant and widely distributed neurotrophin in the mammalian CNS and is expressed throughout the brain, with the highest levels in the neurons of hippocampus (13). In the adult brain, neurotrophins, in particular BDNF, are involved in learning and memory, but they can also support the survival and regenerative sprouting of damaged neurons in the brain. Alterations in BDNF expression in specific neuron subpopulations contribute to various pathologies, including depression, epilepsy, Alzheimer's, Huntington and Parkinson's disease (14, 15). Increased expression of neurotrophic factors in vitro and in vivo is one of the mechanisms of neurotrophic action of flavonoids and is a good therapeutic candidate for neurodegenerative diseases (6). 
Therefore, we hypothesized that the neuroprotective effects of quercetin may be due to increased expression of the BDNF gene. Here, we have investigated BDNF expression in hippocampal tissues of rats treated by oral quercetin.

\section{Materials and methods}

\section{Subjects}

A total of 21 Male Sprague-Dawley rats weighing $250 \pm 20$ $\mathrm{g}$ were provided by the Animal Breeding Center of Shiraz University of Medical Sciences (Shiraz, Iran). Rats were housed in a temperature-controlled room $\left(22 \pm 2{ }^{\circ} \mathrm{C}\right)$ and fed with food and water ad libitum on a 12-h light/dark cycle. Ethics Committee of Shiraz University of Medical Sciences approved these animal experiments.

\section{Treatment schedules and tissue preparation}

Quercetin (Sigma Chemical, USA) was uniformly dispersed in saline containing $10 \%$ ethanol. Rats were randomly assigned to five groups of three animals each. Experimental groups were treated as follows: Saline (C), Ethanol $10 \%$ (vehicle), quercetin in doses of $10 \mathrm{mg} / \mathrm{kg}(\mathrm{Q} 10), 20 \mathrm{mg} / \mathrm{kg}(\mathrm{Q} 20)$ and $50 \mathrm{mg} / \mathrm{kg}(\mathrm{Q} 50)$. Quercetin treatment was administered orally once a day using a gavage syringe for 30 days. The same procedure was used for treating the control group and vehicle group with saline and ethanol, respectively. At the end of the experimental period, animals were sacrificed by decapitation and hippocampal tissues were separated and then stored at $-70{ }^{\circ} \mathrm{C}$ until analysis.

\section{RNA isolation and cDNA synthesis}

Hippocampal tissues were subjected to RNA extraction using Tripure Isolation Reagent (Roche Applied Sciences, Indianapolis, IN), according to manufacturer protocol. The concentrations of extracted RNA were determined by measuring the absorbance at 260 and $280 \mathrm{~nm}$ and the quality of RNA was determined from the absorbance ratio of A260/A280 (A260/A280 > 1.8). 4 $\mu$ g of total RNA was used for cDNA synthesis in a total volume of $20 \mu \mathrm{L}$ by using RevertAid TM First Strand cDNA Synthesis Kit (Fermentas, EU). Synthesized cDNA was kept at $-70{ }^{\circ} \mathrm{C}$ until used.

\section{Real-time $q R T-P C R$}

Real-Time qRT-PCR was performed with a Bio-Rad multicolor real time PCR detector, and iQ5 thermal cycler system (Bio-Rad). The level of expression of the BDNF gene was normalized to the level of expression of the GAPDH gene. Primers for forward 5'-GTGACARTATTAGCGAGTGGG-3' and reverse 5'-GGGTAGTTCGGCATTGC-3' were used to detect BDNF, producing a $212 \mathrm{bp}$ fragment (16). GAPDH primers for forward 5'-TCACCCAACACTGTGCCCATCTACGA-3' and for reverse 5'-TCGGTGAGGATCTTCATGAGGTA-3' were used to produce a 380 bp fragment (17). PCR reaction was performed under the following conditions: An initial denaturation at $95^{\circ} \mathrm{C}$ for $10 \mathrm{~min}$ and then 45 cycle of denaturation at $95{ }^{\circ} \mathrm{C}$ for $40 \mathrm{~s}$ seconds, annealing at $58{ }^{\circ} \mathrm{C}$ for $45 \mathrm{~s}$, extension at $72{ }^{\circ} \mathrm{C}$ for $40 \mathrm{~s}$, and a final

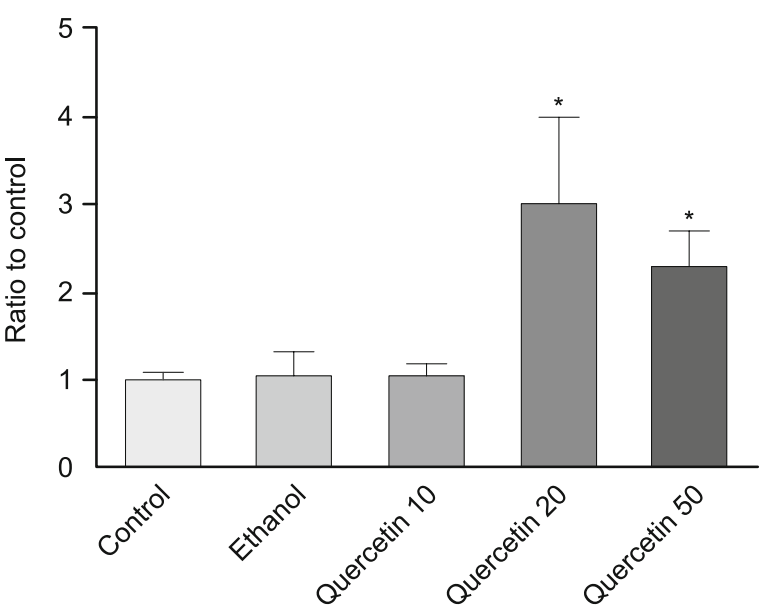

Fig. 1. Comparison of BDNF gene expression between test and control groups in the hippocampus of rats fed with different doses of quercetin $(10,20$ and $50 \mathrm{mg} / \mathrm{kg}$ bwt) using quantitative real-time PCR. The relative expression level of each sample was calibrated by the comparative threshold cycle method, using GAPDH as an endogenous control. Data are presented as the ratio of levels of mRNA for BDNF gene in treated rats to the average of those in the saline treated animals. Oneway ANOVA and a post hoc LSD test were performed for analyzing the data. Data are mean \pm SEM. The asterisk represents a significant increase in the relative expression of BDNF transcript $(p<0.05)$ as compared with the control group.

extension at $72{ }^{\circ} \mathrm{C}$ for $10 \mathrm{~min}$. All experiments were run in duplicate. $2^{-\Delta \Delta C T}$ method was used to calculate the relative expression level (fold changes) of the BDNF gene in the hippocampal tissues of test rats to those of control animals.

\section{Statistical analysis}

All data are represented as mean \pm SEM. One-way ANOVA with LSD post-hoc test was used for comparison between ratios of BDNF mRNA expression in the test and control samples. A p value of $<0.05$ was considered as statistically significant. Data were analyzed with SPSS10 analytic software (SPSS, Inc., Chicago).

\section{Results}

To obtain more detailed information about neuroprotective mechanisms of quercetin in brain, we investigated effects of various doses $(10,20$ and $50 \mathrm{mg} / \mathrm{kg}$ bwt) of this compound on the mRNA expression of BDNF in the brain. As shown in Figure 1, treatment of rats by quercetin at doses of 20 and $50 \mathrm{mg} / \mathrm{kg}$ bwt caused a significant $(\mathrm{p}<0.05)$ upregulation of mRNA expression of BDNF as compared to control groups. To test the possible interference of ethanol with our data, we orally treated a group of rats by ethanol $10 \%$ for the same period of time as described in the methods section. Our data showed that the levels of BDNF mRNA in the hippocampus of ethanol group of rats were not significantly different from those of saline treated animals. Therefore, ethanol $10 \%$ did not affect our results. 


\section{Discussion}

In the present study, to investigate the possible mechanisms of neurotrophic actions of quercetin (3), we determined the expression of BDNF using real-time PCR in the hippocampus of rats treated with this compound. Our results showed that quercetin could increase the expression of BDNF. Significantly increasing effects of oral quercetin on expression levels of BDNF mRNA were observed when rats received 20 or $50 \mathrm{mg} / \mathrm{kg}$ bwt of quercetin, but at a dose of $10 \mathrm{mg} / \mathrm{kg}$ bwt quercetin failed to induce expression of BDNF.

The bioflavonoid quercetin which is widely distributed in fruits and vegetables (9) has drawn much attention for its key biological functions, such as anti-oxidant properties as well as neurotrophic and anti-carcinogenic activities (18). In vitro and in vivo studies have shown that neuroprotective effects of quercetin are exerted by different molecular mechanisms (19). Our study, in converge with these works, suggested a new possible mechanism for neuroprotection by quercetin. BDNF and its signaling pathway is one of the most important of factors involved in neuroprotection (20). Results of the present study show that quercetin up-regulates the expression of BDNF mRNA in the hippocampus. Our observation is in line with a recent report showing that quercetin increased expression of BDNF and attenuated oxidative stress in the hippocampus of rats with high fat diets (21).

Quercetin has also shown protective effects against $A \beta$-induced toxicity in Alzheimer's disease (22). Indeed, quercetin destabilizes and increases the clearance of abnormal proteins such as beta-amyloid peptide and also hyperphosphorylated tau protein (23). Other neuroprotection mechanisms have been postulated for quercetin including regulation of synaptic plasticity, learning and neuronal adaptation via signaling pathways of the PGC- $1 \alpha /$ FNDC5/BDNF, ERK/CREB/BDNF, PI3K/AKT/Nrf2 and activation of SIRT1 (22-24). Therefore, quercetin interactions with these pathways may be responsible for its role in the central nervous system. In contrast, another result suggests that acute administration of quercetin impairs cognitive function by suppression of pAkt, which, in turn, decreases PCREB expression in the hippocampus (25).

Many studies state that oxidative stress could be the major cause of neurodegenerative disorders such as Parkinson and Alzheimer's disease $(26,27)$. In neuronal culture, quercetin increases survival against oxidative insults and appears important for neuronal protection (28). Studies in animal models have also provided supportive evidence for neuroprotective effects of quercetin (3). These activities of quercetin have been attributed mainly to its antioxidant capacity, such as its free radical scavenger activity and by the induction of Nuclear factor (erythroid-derived 2)-like 2 and the consequent upregulation of antioxidant enzymes $(28,29)$. There are some studies on the in vivo effects of quercetin in patients suffering from a disease which is associated with oxidative stress such as high blood pressure (30), sarcoidosis (31) and rheumatoid arthritis (32). These studies suggest that quercetin improves antioxidant defense system and reduces pro-inflammatory cytokines such as TNF $\alpha$ and IL-8. Several studies have also demonstrated that various polyphenols with neuroprotective activity such as resveratrol, apigenin, luteolin and green tea increase expression of BDNF mRNA (33-35). In our previous studies we showed that oral resveratrol induced the expression of various BDNF transcripts in the hippocampus of rats $(7,36)$.

It is noteworthy that quercetin has also been reported to display some adverse health effects. Toxic effects of quercetin are attributed to oxidized products produced during its anti-oxidative activities. These oxidized products are able to attack thiol groups in proteins (29).

It is well established that neurotrophic family members are required for development and survival of neuron (37). BDNF is the most promising neurotrophic factors in the survival and regenerative sprouting of damaged neurons in the brain (38). Animals with reduced expression of BDNF showed deficits in learning and memory (39). Nowadays, increased attention is observed towards strategies aimed at inducing the expression of endogenous neurotrophic factors including BDNF as a way for preserving neurons or for restorative treatment of neurodegenerative diseases (40). Presently, we have observed that treatment with oral quercetin increased BDNF levels in the rat hippocampus. This finding suggests that quercetin has neurotrophic potential and may have beneficial effects on the survival of hippocampal neurons. Accordingly, agents like quercetin that induce the expression of BDNF are conceivable to mimic the biological effects of neurotrophin and have therapeutic values for neurodegenerative diseases.

In conclusion, the present findings are one of the earliest studies showing that oral quercetin increases the expression of BDNF gene in the hippocampus of rats. These results might explain the molecular basis of neuroprotective properties of quercetin.

\section{References}

1. Cirmi S, Ferlazzo N, Lombardo GE, Ventura-Spagnolo E, Gangemi S, Calapai G, Navarra M. Neurodegenerative Diseases: Might Citrus Flavonoids Play a Protective Role? Molecules 2016; 21 (10).

2. Manoharan S, Guillemin GJ, Abiramasundari RS, Essa MM, Akbar M, Akbar MD. The Role of Reactive Oxygen Species in the Pathogenesis of Alzheimer's Disease, Parkinson's Disease, and Huntington's Disease: A Mini Review. Oxid Med Cell Longev 2016; 2016: 8590578.

3. Costa LG, Garrick JM, Roque PJ, Pellacani C. Mechanisms of Neuroprotection by Quercetin: Counteracting Oxidative Stress and More. Oxid Med Cell Longev 2016; 2016: 2986796.

4. Gomes-Rochette NF, Da Silveira Vasconcelos M, Nabavi SM, Mota EF, Nunes-Pinheiro DC, Daglia M, De Melo DF. Fruit as Potent Natural Antioxidants and Their Biological Effects. Curr Pharm Biotechnol 2016; 17 (11): 986-993.

5. Vauzour D, Vafeiadou K, Rodriguez-Mateos A, Rendeiro C, Spencer JP. The neuroprotective potential of flavonoids: a multiplicity of effects. Genes \& nutrition 2008; 3 (3-4): 115-126.

6. Moosavi F, Hosseini R, Saso L, Firuzi O. Modulation of neurotrophic signaling pathways by polyphenols. Drug Des Devel Ther 2016; $10: 23-42$.

7. Rahvar M, Nikseresht M, Shafiee SM, Naghibalhossaini F, Rasti M, Panjehshahin MR, Owji AA. Effect of oral resveratrol on the BDNF gene expression in the hippocampus of the rat brain. Neurochem Res 2011; 36 (5): 761-765.

8. Anand David AV, Arulmoli R, Parasuraman S. Overviews of Biological Importance of Quercetin: A Bioactive Flavonoid. Pharmacogn Rev 2016; 10 (20): 84-89. 
9. Oboh G, Ademosun AO, Ogunsuyi OB. Quercetin and Its Role in Chronic Diseases. Adv Exp Med Biol 2016; 929: 377-387.

10. Spencer JP, Rice-Evans C, Williams RJ. Modulation of pro-survival Akt/protein kinase B and ERK1/2 signaling cascades by quercetin and its in vivo metabolites underlie their action on neuronal viability. J Biol Chem 2003; 278 (37): 34783-34793.

11. Angeloni C, Spencer J, Leoncini E, Biagi P, Hrelia S. Role of quercetin and its in vivo metabolites in protecting $\mathrm{H} 9 \mathrm{c} 2$ cells against oxidative stress. Biochimie 2007; 89 (1): 73-82.

12. Cattaneo A, Cattane N, Begni V, Pariante CM, Riva MA. The human BDNF gene: peripheral gene expression and protein levels as biomarkers for psychiatric disorders. Transl Psychiatry 2016; 6 (11): e958.

13. Yan Q, Rosenfeld R, Matheson C, Hawkins N, Lopez O, Bennett L, Welcher A. Expression of brain-derived neurotrophic factor protein in the adult rat central nervous system. Neurosci 1997; 78 (2): 431-448.

14. Cattaneo E, Zuccato C, Tartari M. Normal huntingtin function: an alternative approach to Huntington's disease. Nat Rev Neurosci 2005; 6 (12): 919-930.

15. Russo-Neustadt AA, Chen MJ. Brain-derived neurotrophic factor and antidepressant activity. Curr Pharm Des 2005; 11 (12): 1495-1510.

16. Zou J, Crews F. CREB and NF-kappaB transcription factors regulate sensitivity to excitotoxic and oxidative stress induced neuronal cell death. Cell Mol Neurobiol 2006; 26 (4-6): 385-405.

17. Takuma K, Matsuo A, Himeno Y, Hoshina Y, Ohno Y, Funatsu Y, Arai $\mathbf{S}$ et al. 17 beta-estradiol attenuates hippocampal neuronal loss and cognitive dysfunction induced by chronic restraint stress in ovariectomized rats. Neurosci 2007; 146 (1): 60-68.

18. Sugantha Priya E, Selvakumar K, Bavithra S, Elumalai P, Arunkumar R, Raja Singh P, Brindha Mercy A et al. Anti-cancer activity of quercetin in neuroblastoma: an in vitro approach. Neurol Sci 2014; 35 (2): 163-170.

19. Tchantchou F, Lacor PN, Cao Z, Lao L, Hou Y, Cui C, Klein WL et al. Stimulation of neurogenesis and synaptogenesis by bilobalide and quercetin via common final pathway in hippocampal neurons. J Alzheimers Dis 2009; 18 (4): 787-798.

20. Nguyen N, Lee SB, Lee YS, Lee KH, Ahn JY. Neuroprotection by NGF and BDNF against neurotoxin-exerted apoptotic death in neural stem cells are mediated through Trk receptors, activating PI3-kinase and MAPK pathways. Neurochem Res 2009; 34 (5): 942-951.

21. Xia SF, Xie ZX, Qiao Y, Li LR, Cheng XR, Tang X, Shi YH et al. Differential effects of quercetin on hippocampus-dependent learning and memory in mice fed with different diets related with oxidative stress. Physiol Behav 2015; 138: 325-331.

22. Liu R, Zhang TT, Zhou D, Bai XY, Zhou WL, Huang C, Song JK et al. Quercetin protects against the Abeta (25-35)-induced amnesic injury: involvement of inactivation of rage-mediated pathway and conservation of the NVU. Neuropharmacology 2013; 67: 419-431.

23. Suganthy N, Devi KP, Nabavi SF, Braidy N, Nabavi SM. Bioactive effects of quercetin in the central nervous system: Focusing on the mechanisms of actions. Biomed Pharmacother 2016; 84: 892-908.

24. Liu P, Zou D, Yi L, Chen M, Gao Y, Zhou R, Zhang Q et al. Quercetin ameliorates hypobaric hypoxia-induced memory impairment through mitochondrial and neuron function adaptation via the PGC-1alpha pathway. Restor Neurol Neurosci 2015; 33 (2): 143-157.

25. Jung WY, Park SJ, Park DH, Kim JM, Kim DH, Ryu JH. Quercetin impairs learning and memory in normal mice via suppression of hippocampal phosphorylated cyclic AMP response element-binding protein expression. Toxicol Lett 2010; 197 (2): 97-105.
26. Campolo M, Casili G, Biundo F, Crupi R, Cordaro M, Cuzzocrea S, Esposito E. The Neuroprotective Effect of Dimethyl Fumarate in an MPTPMouse Model of Parkinson's Disease: Involvement of Reactive Oxygen Species/Nuclear Factor-kappaB/Nuclear Transcription Factor Related to NF-E2. Antioxid Redox Signal 2017.

27. Prasad KN. Oxidative stress and pro-inflammatory cytokines may act as one of the signals for regulating microRNAs expression in Alzheimer's disease. Mech Ageing Dev 2016.

28. Arredondo F, Echeverry C, Abin-Carriquiry JA, Blasina F, Antunez K, Jones DP, Go YM et al. After cellular internalization, quercetin causes Nrf2 nuclear translocation, increases glutathione levels, and prevents neuronal death against an oxidative insult. Free Radic Biol Med 2010; 49 (5): 738-747.

29. Boots AW, Haenen GR, Bast A. Health effects of quercetin: from antioxidant to nutraceutical. Eur J Pharmacol 2008; 585 (2-3): 325-337.

30. Serban MC, Sahebkar A, Zanchetti A, Mikhailidis DP, Howard G, Antal D, Andrica F et al. Effects of Quercetin on Blood Pressure: A Systematic Review and Meta-Analysis of Randomized Controlled Trials. J Am Heart Assoc 2016; 5 (7).

31. Boots AW, Drent M, de Boer VC, Bast A, Haenen GR. Quercetin reduces markers of oxidative stress and inflammation in sarcoidosis. Clin Nutr 2011; 30 (4): 506-512.

32. Javadi F, Ahmadzadeh A, Eghtesadi S, Aryaeian N, Zabihiyeganeh M, Rahimi Foroushani A, Jazayeri S. The Effect of Quercetin on Inflammatory Factors and Clinical Symptoms in Women with Rheumatoid Arthritis: A Double-Blind, Randomized Controlled Trial. J Am Coll Nutr 2017; 36 (1): 9-15.

33. Moriya J, Chen R, Yamakawa J, Sasaki K, Ishigaki Y, Takahashi T. Resveratrol improves hippocampal atrophy in chronic fatigue mice by enhancing neurogenesis and inhibiting apoptosis of granular cells. Biol Pharm Bull 2011; 34 (3): 354-359.

34. Patil SP, Jain PD, Sancheti JS, Ghumatkar PJ, Tambe R, Sathaye S. Neuroprotective and neurotrophic effects of Apigenin and Luteolin in MPTP induced parkinsonism in mice. Neuropharmacology 2014; 86: 192-202.

35. Gundimeda U, McNeill TH, Fan TK, Deng R, Rayudu D, Chen Z, Cadenas $\mathbf{E}$ et al. Green tea catechins potentiate the neuritogenic action of brain-derived neurotrophic factor: role of 67-kDa laminin receptor and hydrogen peroxide. Biochem Biophys Res Commun 2014; 445 (1): 218-224.

36. Shojaei S, Ghavami S, Panjehshahin MR, Owji AA. Effects of Ethanol on the Expression Level of Various BDNF mRNA Isoforms and Their Encoded Protein in the Hippocampus of Adult and Embryonic Rats. Int $\mathrm{J}$ Mol Sci 2015; 16 (12): 30422-30437.

37. Huang EJ, Reichardt LF. Neurotrophins: roles in neuronal development and function. Annu Rev Neurosci 2001; 24: 677-736.

38. Jiao Y, Palmgren B, Novozhilova E, Englund Johansson U, SpielesEngemann AL, Kale A, Stupp SI et al. BDNF increases survival and neuronal differentiation of human neural precursor cells cotransplanted with a nanofiber gel to the auditory nerve in a rat model of neuronal damage. Biomed Res Int 2014; 2014: 356415.

39. Linnarsson S, Bjorklund A, Ernfors P. Learning deficit in BDNF mutant mice. Eur J Neurosci. 1997; 9 (12): 2581-2587.

40. Cimini A, Gentile R, D’Angelo B, Benedetti E, Cristiano L, Avantaggiati ML, Giordano A et al. Cocoa powder triggers neuroprotective and preventive effects in a human Alzheimer's disease model by modulating BDNF signaling pathway. J Cell Biochem 2013; 114 (10): 2209-2220.

Received September 25, 2017. Accepted October 20, 2017. 